\title{
Between Food and Respect for Nature: On the Moral Ambiguity of Norwegian Stakeholder Opinions on Fish and Their Welfare in Technological Innovations in Fisheries
}

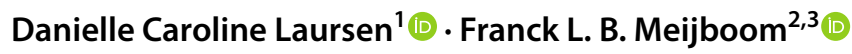

Accepted: 8 February 2021 / Published online: 7 September 2021

(C) The Author(s) 2021

\begin{abstract}
Innovation in fisheries is a global development that focuses on a broad range of aims. One example is a project that aims to develop technology for key phases of the demersal fishery operation to improve product quality and safeguard fish welfare. As this step to include welfare is novel, it raises questions associated with stakeholder acceptance in a wider aim for responsible innovation. How do stakeholders (a) value fish and their welfare and (b) consider the relation between welfare and other relevant values? To address these questions, an approach combining desk research with an empirical study was used. The desk study analysed the ethical and biological arguments for whether fish welfare should be accounted for in this context. The empirical study explored how fish and their welfare are perceived by Norwegian professionals in this industry, by conducting semi-structured interviews and subsequently analysing the results based on a labelling method we developed. The desk study showed a consensus that welfare should be considered in its own right, while at face value the interviews presented a rather instrumental view on this theme. However, analysis of the interview results leads to a more nuanced picture, where fish and their welfare are viewed from the perspective of respect for nature. Despite the apparent divergence between stakeholder opinions and the literature on the importance of welfare, we present three steps that enables professionals to be responsive to both the (moral) views of stakeholders and accounting for welfare in the innovation process fisheries.
\end{abstract}

Keywords Moral status $\cdot$ Fish welfare $\cdot$ Research and development $\cdot$ Semi-structured interviews $\cdot$ Norwegian fisheries

Danielle Caroline Laursen caroline.laursen@gmail.com

Extended author information available on the last page of the article 


\section{Introduction}

There is a broad range of motivations for developing technology in the context of commercial fisheries, a practice that refers to the capture of wild fish and other consumable species for profit. Occupational health and safety (Digre et al., 2017), product quality (Digre et al., 2010; Olsen et al., 2013), or sustainability (Svanes et al., 2011; Thrane et al., 2009) are a few examples of themes that are focused on. Animal welfare, however, has until recently not been considered a motivation in its own right for innovating in this context. The welfare of fish remains a relatively novel concept in the practice of commercial fisheries and has received little attention in research and development to date (Huntingford et al., 2006; Lambooij et al., 2012). Reasons for this lack of attention may be due to the fact that knowledge in this area is limited (Veldhuizen et al., 2018). However, there may also be more fundamental moral reasons; there is still a diversity of views on what we owe to fish (Bovenkerk \& Meijboom, 2020). Nevertheless, fish welfare in the commercial fisheries setting is expected to become a significant issue in the future (Kaiser \& Huntingford, 2009; Lambooij et al., 2012). Therefore, it is relevant to address the concerns for fish welfare through technological development, i.e. developing new and improving on existing methods.

The current study is part of a recent research project in Norway that focuses on developing more humane capture and slaughter methods in commercial fisheries to account for product quality and animal welfare. This step to include animal welfare as an aim for developing specific technology raises questions that are ultimately related to a broader objective for responsible innovation. Facilitating successful research and development relies in part on stakeholder acceptance of the technology that is being developed. Therefore, stakeholder opinion plays an important role in guiding the entire process of research and development (Owen et al., 2013). This holds true for any process of innovation but seems especially relevant in the context of this project, where fish welfare is seen as a relatively novel theme and where moral plurality exists. Therefore, we conducted an explorative empirical study to gain insight into how Norwegian stakeholders in the fisheries sector perceive and value fish and their welfare. Furthermore, how these stakeholders consider the relation between animal welfare and other values such as, for example, profitability, product quality, or health and safety.

The approach taken in this study was to combine desk research with the empirical study. Desk research was done to make an analysis of the ethical and biological arguments to determine whether fish welfare ought to be accounted for in its own right and why. The empirical study involved carrying out a small number of semi-structured interviews with professionals in the fishery sector involved in or affected by the innovation process.

The results from the current study are presented in this paper along these lines: it starts with a short description of background information to the project is given in order to provide an understanding of the context of the project. This is followed by output from the desk research, which is an overview of the discussion on the moral position of fish and how the different positions in this debate link 
welfare in the context of using fish for food production. This output has been used as input for the empirical study that will be introduced in the "Methodology" section of the paper. Next, the findings from the semi-structured interviews are presented in the "Results" section. Finally, the results are discussed and analysed; they are compared with the findings from the desk study and discussed with the help of ethical theories. As a conclusion, the implications of the analysis and findings for the technological developments that aim to improve welfare are briefly discussed.

\section{Background}

The mentioned recent research project makes specific reference to the bottom trawl fishery operation for demersal whitefish species, i.e. cod (Gadus morhua), haddock (Melanogrammus aeglefinus) and saithe (Pollachius virens), in Norway as a case study.

The bottom trawl fishery operation consists of towing a funnel or cone shaped net along the seabed by a vessel at a wide range of depths. In brief, this process consists of different phases: capture, hauling and slaughter. The trawl net gear consists of a body ending in a bag at the rear, i.e. cod-end, where the target species are collected. During the capture phase, individuals are guided into the net as the trawl gear moves through an aggregation of fish and accumulate in the con-end (Winger et al., 2010). When the appropriate catch volume has been accumulated, the trawl system and catch are hauled in (Gjøsund, 2018, pers. comm.). After the catch has been hauled in, the fish are usually transferred to holding bins without water onboard the fishing vessel until they are slaughtered by bleeding (Erikson, 2018, pers. comm.).

It has been recognised that the different phases of the bottom trawl fishing process can have impacts on the fish, at the individual level. During the capture phases, the fish try to swim in line with the trawl net opening until they become physically exhausted (Gjøsund et al., 2011) and fall back into the body of the trawl net, eventually accumulating in the cod-end (Winger et al., 2010). Once they have entered the cod-end, the fish may experience gear-specific traumas (Metcalfe, 2009) due to hydrodynamic pressure, surrounding catch and netting and individuals are often (mortally) injured during this process. During hauling, the fish can be exposed to a rapid decrease in pressure, which can cause gas filled or burst swim bladders and abdominal cavities as well as tissue damage. The fish are also held at very high densities during hauling, which can induce stress and skin damage due to contact with netting and abrasion with other fish (Lambooij et al., 2012). Some of the fish die as a direct consequence of the catching and hauling phases before they are intentionally slaughtered. Those individuals that are still alive when landed onboard the fishing vessel (Metcalfe, 2009) may die from anoxia before they are slaughtered, which can cause stress.

The consequences of such impacts to the fish are potential effects on product quality and value (Digre et al., 2010). Furthermore, as individuals are exposed to pain and stress, they may therefore experience suffering (Lambooij et al., 2012; Veldhuizen et al., 2018). This suggests that the welfare of the fish could be compromised 
(Huntingford et al., 2006). Therefore, the wider research project focuses on developing specific technology for key phases of the demersal fishery operation to take product quality and the welfare of fish into account. The research project focuses on two aspects of the this fishery operation and proposes to develop: (1) more humane slaughter methods onboard the trawler vessel, by assessing the application of electrical stunning while pumping the fish onboard the trawler vessel (Erikson and van de Vis, 2018 pers. comm.), and (2) a more gentle capture method, by altering the design of the trawl cod-end to allow the fish more space and calmer flow conditions, thereby potentially reducing stress, exhaustion and mechanical damage (Gjøsund et al., 2011).

This research project, with proposed concepts for technological innovation that aim to take the welfare of fish into consideration, provides a basis for the ethical analysis and empirical study presented in this paper.

\section{On the Moral Status and Welfare of Animals: The Special Position of Fish}

The attention to the welfare of fish not only raises questions for technological innovation, it also touches upon more fundamental ethical questions; whether and under what conditions animals are members of the moral community and why welfare should be taken into consideration. This links to the ethical discussion on what we owe to animals. This debate often starts with the question of whether they have moral status, i.e. whether they are beings to which we can have direct duties (Goodpaster, 2013; Warren, 1997). In this debate, the proposed criteria reflect a broad range, including the capacity to flourish, being sentient, having autonomy or dignity, and having the ability to enter social relationships. On an academic level, we lack one clear and shared set of criteria that are considered necessary and sufficient for having moral status. Nonetheless, there appear to be two trends reflected in the academic literature, as well as in public surveys and government documents. Firstly, there is an increasing consensus in the Western world to include mammals as part of the moral community and as a result, acknowledge that we have moral duties towards them. This is reflected in an increase in animal welfare legislation (European Commission [EC], 2007; Stevenson et al., 2014) and public debate on the acceptability of certain types of animal use, such as meat and fur production or hunting for sport (European Union [EU], 2016; Schukken et al., 2019). Secondly, there is a trend towards taking sentience as the most widely accepted criterion for determining moral status (cf. Broom, 2016; DeGrazia, 2008; Lund, 2007). But how do these trends apply to the case of fish?

Debates on the moral position of fish and the duties towards them are not completely absent, yet they are still a novel case with regards to the application of ethical concepts (Knutsson \& Munthe, 2017; Lund et al., 2007; Meijboom \& Bovenkerk, 2013). Do fish count in our moral reasoning and if so, why and how? Despite such questions being increasingly discussed, there is a plurality of views on the moral status of fish and the moral duties towards them. At one end of the spectrum, fish are viewed only in terms of instrumental value, whilst others argue 
that fish are morally considerable for their own sake. Yet, even in discussions on animal rights, fish are rarely mentioned (Francione \& Garner, 2010).

Recent scientific developments regarding the pain perception of fish have fuelled the ethical debate by providing evidence that they may possess the biological infrastructure to feel pain, i.e. nervous system and brain structures for nociception, at a behavioural and physiological level (Sneddon, 2011). It has been argued by some that this evidence suggests that fish may be capable of experiencing suffering (Braithwaite, 2010; Chandroo et al., 2004), thereby classifying them as sentient beings (Woodruff, 2017) which is a pre-requisite for having interests that can be harmed (i.e. being morally considerable). On the other hand, there is still uncertainty with regards to the further cognitive capacities of fish (Allen, 2013; Rose, 2002; Rose et al., 2014), i.e. whether they have the capacity for consciousness, putting into question the sentience of fishes (Arlinghaus et al., 2007; Browman et al., 2019).

Despite there being both moral plurality with regards to the moral position of fish and scientific uncertainty regarding the capacity for pain perception in fish, attitudes towards fishes are changing. Fish are considered as a part of the moral community more often and it is acknowledged that, to at least some degree, we can have moral duties towards them (Bovenkerk \& Meijboom, 2020; Dutch Council of Animal Affairs, 2018; Knutsson \& Munthe, 2017). This is also reflected in a fairly wide range of concerns amongst citizens / consumers, researchers, NGO's and industry with regards to fish welfare in relation to capture fisheries and fish farming (Kalshoven \& Meijboom, 2013; Kupsala et al., 2013; Röcklinsberg, 2015). Furthermore, there have been several developments in recent years to include fish and their welfare in national animal welfare regulations and recommendations (Lund et al., 2007; Norwegian Council for Animal Ethics, 2014).

Clearly the reasons that underlie this concern for fish welfare are diverse and still reflect the mentioned plurality and uncertainty. These range from reasons that start in a moral obligation to treat animals in our care humanely to those who recognise a potential win-win reality of keeping aquatic animals in a state of good welfare (Browman et al., 2019). Nonetheless, the welfare of fish has been identified as a value or interest that we ought to take into consideration. This also applies to wild-caught fish in the context of capture fisheries, despite the novelty of the attention. A study by Veldhuizen et al. (2015) looked at identifying the relevant social sustainability issues for cod and haddock fisheries in the northeast Atlantic and determining the importance of these issues based on stakeholder input. In general, although the study determined fish welfare (described as 'fish welfare during capture' and 'humane slaughter of fish') to be one of the least important social sustainability issues, it was identified as one of several new social sustainability issues (Veldhuizen et al., 2015).

In light of the aim of the current project to take the welfare of fish into consideration, the perspective taken here will be one characterised by trends towards the changing position of fish and their welfare as a start, but with the recognition that a further understanding of reasons that underlie this trend and views of those who work in this practice is necessary. 


\section{Methodology}

\section{Desk Study}

As a first step towards the empirical study, the results from desk research on ethical (including animal welfare) and natural science literature were combined with a list of relevant stakeholders. During this process the Ethical Matrix (Mepham, 2000) was used to make a preliminary structuring of the ethical issues and possible blind spots present in the context of this project. This preliminary structuring was presented and discussed with the wider research group involved in the project. This process helped to structure the interview guide subsequently used in the empirical study (see "Semi-structured Interviews" section for further details). It also led to the establishment of a preliminary set of labels that was used for assessing the information gained from the interviews (see "Data Analysis" section for further details).

\section{Empirical Study}

To be responsive in the process of responsible innovation in the practice of fisheries and society in general, an empirical study was of added value. The aim was to integrate the results from an empirical study into the ethical discussion (Van der Scheer \& Widdershoven, 2004), by providing insight into the views held by professionals working in this context on the fundamental ethical concepts. Specifically, how the relevant stakeholders: (a) view and value fish and their welfare, and (b) consider the relation between animal welfare and other values relevant in this practice. With regards to the first aspect, there was a need to gain more of an understanding of how fundamental ethical concepts, such as the moral status of fish and animal welfare, are perceived in practice. The latter aspect was especially relevant for the process of technological innovation as specified in this project.

\section{Stakeholders}

The focus of the empirical study was on professionals involved in the fisheries sector, especially those involved in trawl fishing in Norway because of the context of the research project. Specifically, the emphasis was those individuals involved in the innovation process or its immediate results. As the opinions of animal welfare organisations and other NGO's on the position of fish and animal welfare are more explicit and easier to access, the decision was made to focus the research on other relevant professionals in the sector whose views have yet to be made clear. As a result, four categories of relevant stakeholders were identified: (1) whitefish trawl fishing companies, (2) research institutions involved in gear technology, (3) trawl gear suppliers and (4) policy makers. Ten persons in total were interviewed. Of the approximately 15 whitefish trawl companies in operation in 
Norway in 2018 (Gjøsund, 2019, pers. comm.), four were interviewed. Two out of the circa six trawl gear suppliers, two research institutions and one policy maker were interviewed.

\section{Semi-structured Interviews}

As the aim of this empirical study was to explore and map the views and values of the stakeholders involved, a semi-structured interview was determined to be the most appropriate method for gathering the empirical results. The advantage of a semi-structured interview is that it allows the interviewee to freely discuss their opinions and views on the topics of interest for the study. At the same time, the method allows the interviewer the possibility to impose a certain structure to the interview (Kalshoven \& Meijboom, 2013; Turner III, 2010).

Based on the desk study (described in "Desk study" section), it was determined that it was important to acquire: (a) a general idea about what values motivate stakeholders to work in their profession in this practice, (b) a first idea about how they value fish and animal welfare and (c) stakeholder's overall attitudes towards technology, with special reference to the concepts being investigated in this current project. As a result, five topics of interest or themes were established: (1) professional motivation, (2) identification of value assumptions, (3) perspectives on the relationship between humans and fish, (4) views on the concept of animal welfare, and finally (5) attitudes towards the development of new technology.

During the interviews, the interviewees were asked open-ended questions that covered the five themes. The questions were prepared in advance and structured in an interview guide, that was used as a reference by the interviewer during the interview. The interviewer sought to ask the same or similar questions to each interviewee, although the sequence of the questions may have varied slightly between the interviews in response to the nature of the dialogue.

\section{Interview Process}

A list of potential interview candidates was compiled through the professional network of the interdisciplinary research team involved in the wider research project. Potential candidates were recruited by the interviewer, by sending an invitation to take part in the interview via e-mail. Positive responses to the invitation were followed up by arranging a suitable meeting date and time.

The ten interviews were carried out during the winter of 2018/2019, between 14 December 2018 and 17 March 2019. To achieve a favourable interview environment, most of the interviews were carried out in person at the workplace of the interviewee $(n=5)$. These were situated at different geographical locations throughout Norway. One of the interviews was carried out at a Norwegian organisation with a location in Denmark. In those cases where it transpired to be unfeasible to arrange a meeting in person, these interviews were carried out by either telephone $(n=3)$ or Skype $(n=2)$. The majority of the interviews were held in Norwegian and/or Danish $(n=9)$. On average, the length of the interviews was one hour. 
Each interview was audio recorded using an audio recording device. At the beginning of each interview, the interviewee was asked if s/he would agree to the interview being audio recorded for the purposes of accuracy and analysis of the content at a later stage. The interviewee was reminded that the interview was being treated as anonymous and that s/he would not be identifiable now or in the future by either name or any other personally recognisable attribute. If the interviewee agreed to this, s/he was given a written consent form to read and sign. The Norwegian Centre for Research Data (NSD) had validated the use of the audio recordings for the purposes described in the current study (prior to the start of empirical study) and that any personal data being processed in relation to the study was done in accordance with the current General Data Protection Regulation (GDPR).

\section{Data Analysis}

After the interview was completed, the content of the audio recording was transcribed and translated in English by the interviewee. The transcript of responses was subsequently analysed for trends by linking quotations to a pre-developed, but open list of labels. The list represented keywords that the both authors anticipated would emerge during the interviews, such as for example profitability, respect, fish welfare = product quality, health \& safety, etc. This list was informed by the desk study on the ethical dimensions of innovation to improve welfare in trawl fisheries (see "Desk Study" section. for further details). The list of labels was refined during the process of data analysis, by adding, removing and/or combining relevant labels. Both authors established trends where there were patterns of repetition of given labels throughout and between interview responses. These have been discussed with the wider project team.

The list of labels was divided into four categories of themes: (1) professional motivation and underlying values, (2) position of fish, (3) fish welfare, and (4) technological innovation. Each theme contained a list of approximately 30 labels, each label given a corresponding code.

\section{Results}

\section{Professional Motivation and Underlying Values}

There is a diversity in forms of motivation regarding why interviewees decided to work in the context of the fisheries sector. Some of the interviewees $(n=4)$ told that they ended up working in the fisheries sector by chance, although a shared motivation expressed by a number of them $(n=6)$ for working in this context is that "it is very interesting". One interviewee mentioned that it is interesting because the profession can be unpredictable, circumstances can change very quickly, and one must therefore make fast decisions. Additionally, there is a whole spectrum of tasks involved in the practice. Another interviewee mentioned that it is an interesting industry to work in because "there is always something new". 
Motivations also differ, in part, between stakeholder category. One of the interviewees working for a trawl fishing company mentioned tradition as a motivation, that $\mathrm{s} /$ he has inherited the tradition from her/his family and that "it was important to continue that tradition". Another interviewee described being a fisherman as "nature, freedom, a challenge, and a lifestyle". S/he explained that when one is working onboard a fishing vessel, one is part of a "miniature community". Two of the interviewees also mentioned that contributing to food safety and security is a motivation for working in commercial fisheries. As one of the interviewees said:

... but to be a fisherman contributes to millions of meals being brought to shore to people who need food, are paid, contributes to the local community ... .

One of the interviewees working for a research organisation mentioned a few reasons for working in this context, from gaining new knowledge, to having good interpersonal relationships with customers and being able to disseminate knowledge that can be used in practice.

Job satisfaction, i.e. why interviewees think what they are doing is worthwhile, varied between stakeholder category. An interviewee working for a trawl fishing company said that job satisfaction is that one's employees are content, and that the business thrives. One interviewee working for a research organisation mentioned progress, that job satisfaction "comes from doing things better". For an interviewee working for a gear supplier, job satisfaction is about trying out new models and ensuring that they work in practice. Alternatively, according to the interviewee working for a policy making authority, it is about "trying to achieve a more justifiable catch".

The interviews also revealed a number of underlying values in the context of the fisheries sector. These dimensions that are important to persons in their professions also varied with stakeholder category. For one of the persons working for a trawl fishing company, a primary goal is delivering a profit; the interviewee said that in his/her profession "it is most important to create economic values".

Investing in technological development is viewed as important, to encourage progress and support social responsibility, by providing interesting jobs for the local community. As the above quoted interviewee continued by saying:

To provide meaningful employment for people and their families. Especially for those in rural communities. To develop new vessels and new processing facilities with state-of-the-art technology that is bringing the industry forward.

Another person working for a trawl fishing company explained that due to the potentially hazardous nature of the profession, a focus is ensuring the safety of the crew onboard the vessels. S/he said that:

Clearly one is concerned about one's employees onboard the vessel and that there must be safe and secure working conditions. Therefore, the boats and safety are at a high level. 
A different interviewee working for a fishing company mentioned that labour relations, i.e. "the rights", of the crew onboard the vessel are valuable. This includes health and safety, as mentioned by a previous interviewee, but also includes the working conditions of employees. The two interviewees working for a research organisation mentioned that it is important to carry out research projects "that are relevant", finding solutions to problems and that the work is done correctly so that it can be used in practice. According to the interviewee working a policy making authority, it is most important "to be part of achieving a sustainable fishery. As s/he stated:

We must harvest from the ocean, but we must do it in a sustainable manner. And to be able to do that, one must not catch more than one should.

\section{Position of Fish}

The interviews showed a trend towards professionals in the fisheries sector viewing fish as a natural resource for human consumption. As one of the interviewees said:

In general, I regard the fish as a resource ....

Indeed, half of the interviewees said that they view fish as either "food" or as "a product for food" or "as a fantastic meal". Furthermore, it was acknowledged by a number $(n=4)$ of the interviewees that fish are living beings but it was mentioned that there is a hierarchy between animals $(n=4)$, where fish tend to be viewed as lower in the hierarchy, i.e. they are different from other animals. It was also mentioned that fish are not capable of feeling anything $(n=1)$ and do not have any emotions $(\mathrm{n}=1)$. As the latter interviewee said:

I do overall not believe that fish are full of emotions. I think they are full of life saving instincts ... we tend to give them a little too many human values.

Nevertheless, despite this rather instrumental way of viewing fish for our own use, the general view that was expressed during the interviews was that fish must be treated with respect and in the most responsible way. Perhaps not per se for the sake of the fish itself, i.e. because of claims that they are able to suffer, but out of respect for the fish as a natural resource $(n=5)$. One interviewee said:

... We try to treat them with respect and in the best possible way.

This respect for nature attitude means that one ought to use the resource in a nonwasteful manner. As one interviewee stated:

... we try as much as possible with those fish that we catch, that we take a manageable amount so that is does not become wasteful. In that way, we try to take account of treating the fish as best as possible.

Another interviewee mentioned that fish should be treated in a responsible way, to safeguard the resource "so that we can feed the population". Another viewpoint expressed by an interviewee is that fish should be treated in the best possible way possible in order to achieve "the best quality". On a similar line of thought, one view 
is that fish should be "treated well so that they can be sold as a high value product for other people's needs and use". Furthermore, other views are that fish should not suffer or be hurt $(n=1)$ and that if they must be killed, then this should be done quickly $(\mathrm{n}=1)$.

During the interviews, it was noted that in one case the interviewee mentioned that there was a difference in how fish are viewed as a private and professional person. Furthermore, another respondent started the discussion during the interview reflecting on the ethical issues in the context of fisheries practices. S/he suggested that compared to other methods of food production the practice is rather "brutal" and that "there are always possibilities to improve things and they have been getting better, also in the fishing industry", although this tone changed throughout the duration of the interview.

\section{Fish Welfare}

A variety of ideas about the meaning of the concept of animal welfare emerged during the interviews. For example, views include that animal welfare means that the animal is "doing well" and is "cared for". The dimension of "doing well" is understood by some in terms of physiologically wellbeing. Others also hint to the notion that welfare entails that the animal is able to live as natural a life as possible $(n=1)$. Furthermore, the majority of interviewees $(n=9)$ tend to include (wild-caught) fish in their ideas regarding the concept of animal welfare.

There was a plurality of views with regards to the scientific discussion on the pain perception of fish. One interviewee does not think that fish are capable of experiencing pain, while another thinks that fish maybe can feel pain and one said that they probably can. A few interviewees responded that they do not know or are unsure, either due to personal uncertainty $(n=4)$, i.e. they do not have enough knowledge about it, or because they are aware that there is scientific uncertainty surrounding the issue $(n=3)$. For example, one interviewee said:

I acknowledge that there are two extremes, one that there is no evidence that fish feel anything, pain or have a pain centre, and the other that shows that fish react to things which suggests that it must feel something. I do not have any knowledge about that ....

Two of the interviewees mentioned that, regardless of whether fish have feelings or can experience pain or not, they are capable of experiencing some type of stress. One of the interviewees said:

I am pretty sure that fish can become stressed, because this is something that has been measured... .

Furthermore, the interviewees emphasize that the stress fish experience during the fishing process has a detrimental effect on the quality of the product or meat, in practice. As the afore-cited interviewee went on to say:

... And the only reason why I think a fish shouldn't become stressed, is because then the quality of the meat will be affected negatively, worse quality. 
Therefore, a view is that it is important to expose them to as little stress as possible, by trying to reduce the amount of time that the fish spend in the fishing gear and by slaughtering them as quickly as possible.

On this line, the general view amongst the interviewees is that fish welfare and product quality are directly linked $(n=8)$. If one treats the fish well and they have good welfare, then one will have a better-quality product. Due to this link to product quality, several of the interviewees suggest that fish welfare is important. As one interviewee stated:

Treating the fish as well as possible starts with fish welfare, because if we do not have a good fish welfare, we do not have a good product. The two are related. In that sense, fish welfare is important.

\section{Technological Innovation}

In general, the interviews revealed a number of motivations for investing in technology in this context. For example, one interviewee stated that a motivation for investing in technology would be if it "provides improvements" that people understand and that they understand how it can be used in practice. More specifically, if the technology can "increase the catch volume", "improve the quality" of the product, and "simplify the work" for the crew onboard the vessel. Furthermore, another interviewee said that there is a motivation to invest in technology, if it can increase "efficiency", result in a "better-paid product" and "safeguard" the resource. However, there were also some reservations with regards to investing in technology. One interviewee stated that it can be costly to "buy new equipment and maintain it". Therefore, another interviewee suggested that it is about finding a balance, between what the market wants or is willing to pay for and the best way of fishing.

With regards to the specific concepts in the current project, the general view from the interviews was that the idea of developing technology to improve fish welfare and product is very relevant $(n=5)$, because it will make the fisheries industry more "sellable in the future" $(n=1)$. Furthermore, a better-quality product is the most important driver for the industry, as it means that fishermen will receive a higher price for their product. As a result, "everybody is satisfied" $(n=1)$. On the other hand, there was also some uncertainty to the specific concepts $(n=5)$. One interviewee expressed the opinion that $\mathrm{s} / \mathrm{he}$ is "a bit unsure" because there are several new methods that do exactly the same thing without there being much improvement. Furthermore, it can be costly, there may not be a market for it and the technology may be unfeasible for use in practice. As one interviewee explained:

Not so much has happened with regards to the fishing and production equipment. And why not? Firstly, it costs a lot of money to try it. And when you know that the market does not want to pay for it, then it is not the motivation to do it. And so, I think it is a bit disappointing to look at, that there is not a bigger development in these areas. And many of the ideas that are there, are maybe not suitable for use in practice. 


\section{Discussion}

\section{Limitations and First Comparison to the Desk Study}

As outlined in the introduction, the aim of this study was to analyse how: (a) views on fish welfare and the moral position of fish in the academic literature relate to the opinions of selected stakeholders and (b) likewise for the discussion on the capacity for pain perception of fish. These two steps aim to contribute to a better informed and more responsive way of innovation in fisheries that take the welfare of fish into account. From this perspective, it is important to note that the results presented in the current study are not and do not intend to be representative for the entire community of persons involved in the commercial fisheries practice. This first stage of the technological development process includes stakeholders that are involved at the level of research and development, rather than focusing only on those in a managerial role. Given our claim that a broad scope of stakeholder opinion is necessary as input for an ethical evaluation, we gave all stakeholders equal importance at this first stage of the responsible innovation process. Furthermore, differentiating between stakeholder groups at this stage and expanding on one specific group (for example, managers) would suggest the need to examine their positions and responsibility on a deeper level, implying a completely new study. Nonetheless, given the fact that some key players in different parts of the chain were selected, the results provide an indication of the views and values of those who are professionally involved in fisheries and research.

When analysing the results and comparing these to the output from the desk study, it is apparent that the results from the interviews do not reflect the full range of moral views mentioned in the literature. With regards to their moral status, fish are mostly considered as a natural resource for human consumption, which seems to be linked to an instrumental view on fish. Furthermore, although fish welfare is mentioned and discussed, it is ultimately also an issue that is currently not given much consideration for its own sake. Finally, the results do reflect the scientific uncertainty in the literature regarding the pain perception of fish. The diversity of views on the capacity of fish for feeling pain was even more prominent than observed in most of the academic literature. The views ranged from the opinion that fish are unable to experience pain to the opinion that they most likely can.

\section{Ethics and Welfare as External Concerns}

The results show that the interviewees clearly have their own personal views on animal welfare and the (potential) moral problems that occur in the context of fisheries. Nonetheless, two interesting trends were observed that both set ethics and animal welfare at a certain distance from the professionals working in this sector.

Firstly, interviewees perceive the drivers for the attention to ethics and welfare as located outside or even opposite of their own practice. Especially in the case of animal welfare, it is perceived to be linked to NGOs $(n=2)$ that are critical of fisheries practices. Consequently, the welfare of fish in the context of fisheries is at face 
value seen as a concept that has been developed by external actors who have their own interests. However, this view of fish welfare is not so absolute. During discussions with the interviewees it became clear that these professionals do in fact have their own ideas about the wellbeing of fish and the moral obligations towards them that follow (elaborated further in the next sections). Furthermore, animal welfare is perceived by the interviewees as an 'import product' introduced by NGO's or government organisations, rather than as a part their own community. This is an obstacle for taking welfare into account due to the special character of the fishing community. For example, one interviewee characterised working onboard a fish vessel as being part of a micro-community, i.e. a society in miniature. Another interviewee stressed local and traditional values of fishing communities. These (micro) communities have their own practices and values, suggesting that there are community values that are already in place for dealing with (ethical and welfare) concerns, such as those more traditional and local values. These may be considered as in conflict with ideas about the importance of fish as represented by NGO's.

Secondly, animal welfare is considered to be external to the professional practice, due to the distinction that is implicitly made between personal morality and professional morality. Moral values and the need for ethical reflection are considered to be important on a personal level rather than being embedded in the profession or in practice. In a single case, it was made explicit and the interviewee distinguished between his/her professional stance and his/her relation to fish in his private life. However, the majority of the interviewees $(n=9)$ did not recognise moral problems in their professions in the context of fisheries that are in need of direct ethical reflection. There was only one interviewee that started the discussion at the beginning of the interview by reflecting on the potential ethical issues of fisheries practices.

\section{Link Between Product Quality, Stress, and Welfare}

The interviews highlighted that product quality is a key concept in the context of trawl fisheries, that is becoming increasingly important, and is a view that is consistent with the one observed in the literature (Digre et al., 2017). Next to valuing quality as such, a few of the interviewees explain the importance of better-quality products by referring to the opportunity to sell for a better price. For all the interviewees, improving on product quality is a primary focus.

Despite the diversity of views about whether fish can feel pain, it appears that stress is recognised as an issue, especially in relation to product quality. One interviewee explained that although there are many aspects to quality and improving on quality, stress is one of the most important. It is generally agreed that the less stress the fish experience, the better the quality of the products yielded from them. As a consequence, there are incentives to reduce stress, by working to find ways of keeping the fish for the shortest possible time. For example, by reducing the amount of time the fish are held in the fishing gear or onboard the vessel before slaughter and slaughtering the fish as quickly as possible. Interestingly, however, the relation between stress and welfare is not explicitly recognised, which implies uncertainty as to whether professionals in this context include stress in the concept of animal 
welfare or whether they consider it an independent topic. In the literature on animal welfare science, stress is certainly viewed as a significant aspect (Ashley, 2007; Conte, 2004; Huntingford et al., 2006).

An interesting trend shown throughout the interviews was the opinion that product quality and (fish) welfare are linked. In other words, although the two concepts are to be distinguished, they are co-dependent in practice. Therefore, if one treats fish well and they have good welfare, then one has better chances for a better-quality product. According to the majority of the interviewees, this was the most important or even the only valid reason to include attention to and implement measures to improve animal welfare in the practice of fisheries.

\section{Moral Ambiguity on the Position of Fish and Their Welfare}

The above sketched view on the welfare of fish suggests starting from a rather instrumental view on the moral position of animals in the context of the fisheries sector. Fish are viewed as a natural resource and as lower on the hierarchy than other animals. Their welfare is not considered to be important for its own sake. Therefore, one would expect that the ideas about how fish ought to be treated would reflect this view. Nonetheless, the responses show a more nuanced or ambiguous picture. The interviews revealed that fish, although viewed as a natural resource, deserve respect and careful handling. This point of view does not directly start in the acknowledgement of the moral status of the individual animals but refers to an attitude of respect for nature or natural resources on a population level. As a result, this attitude of respect translates into treating them well and in a responsible manner.

To understand and interpret these views onto what one owes to fish, one should be hesitant to jump to conclusions. The ideas that are formulated in the interviews often seem to start in a lay utilitarian account (cf. Lund et al., 2019). This is in the sense that the claims that one should care for fish and their welfare refers to the contribution to a good quality product. Although implicit, it refers to the idea that if welfare contributes to product quality it also contributes to overall happiness. This is referred to as a lay utilitarian account in this case as it includes components from a utilitarian ethics approach but lacks the more systematic assessment that aims at maximising overall happiness. Furthermore, the picture is complemented by elements from other ethical traditions. On the one hand, the above-mentioned reference to respect for nature fits ethical accounts that have a more biocentric outlook (cf. Taylor, 1986) and look to animals as part of an ecosystem rather than as individuals. As a consequence, fish should be treated with respect, but mainly because they are part of nature. On the other hand, there are also claims on how we should treat fish that seems to refer to elements from a virtue ethics approach. For instance, the notion that being a "good" fisherman or other professional in this practice implies attention to and care for fish. Although the virtue of compassion for individual fish (cf. Hursthouse, 2006) is not recognisable in the answers given by the stakeholders during the interviews, some implicitly recognise that insensitivity is not considered virtuous and that implies that one should do well by fish. 


\section{Implications for Technological Innovation}

The interviews revealed that there is a generally positive attitude towards technological innovation. Furthermore, developing or improving on technology that has the potential to deliver a better-quality product is supported as relevant by the interviewees. However, hesitance was expressed by the interviewees when the technology does not contribute to the value of the product. In that sense, the ethical discussion surrounding technological development follows a more instrumental and economic focus, where the fish is mainly seen as a product and there is not a focus on a respect for nature. Thus, the ambiguity in the ethical discussion that was observed under the theme of moral status and animal welfare is absent in the discussion surrounding technological innovation.

Furthermore, the discussion under this theme is on the one hand, whether the technology that is being developed can provide added value and on the other hand, the cost associated with that technology. As the results imply, this potential cost can be experienced on two levels. One aspect is that it can be expensive to buy and maintain new technology. The second aspect is that the cost is more related to the market and whether there is an infrastructure that can allow for this type of innovation to be profitable. According to two of the interviewees, the challenge here is that there may not be a market that is willing to pay for a product that is more expensive as a result of a better-quality. However, this perspective would require further study and analysis at a market level, with specific reference to the types of innovations being developed in the current project and on a more general level for the sustainable development of fisheries.

\section{Conclusions}

At face value, the interviews revealed a rather instrumental view on the position of fish and their welfare and showed that the concept of fish welfare is still a novel concept within this context that has currently not been given much consideration for its own sake. This view on fish as a resource if further emphasised by the market structures in which most of the interviewees operate. The market treats fish mainly as a commodity and therefore it may not come as a surprise that the professionals that work in this context have learned to speak and act from this market perspective. As a result, fish are also viewed in a more instrumental way, also in the discussion surrounding technological innovation.

However, this is not the full picture of how the interviewees perceive and evaluate fish. Next to the dominant view on fish as a natural resource, they refer to frameworks in which the position of fish and their welfare are viewed from the perspective of respect for nature or being a virtuous professional. In this way the perception of the stakeholders differs from the animal welfare literature that often focuses on the interest of individuals rather than start from the respect for nature (cf. Bovenkerk \& Verweij, 2016).

This ambiguity in the views of the interviewed stakeholders seems to make it difficult to identify how fish welfare should be included in future research and 
development in the context of commercial fisheries. Nonetheless, we see three steps to develop and implement technology to improve animal welfare in a way that do justice to the views on fish welfare that have been collected in this study. Firstly, this study shows that product quality could be used as a link to integrating animal welfare into the (trawl) fishery operation. The advantage is that stakeholders highlight this as a key concept and already recognise that it is can be connected to the concept of welfare. This link between product quality and welfare has been acknowledged in other contexts, such as in aquaculture, where under certain circumstances good welfare can lead to superior product quality (Browman et al., 2019).

Secondly, the indication that stakeholders refer to values linked to respect for nature and to professional virtues are an important entry point. From a respect for nature view there is room to include animal welfare into the practice of fisheries as has been shown in the philosophical literature (e.g., Taylor, 1986). Rather than an individualistic and sentience account, an approach that starts in respect for nature and reference to professional view of care and community seems promising to discuss with stakeholders in research and innovation that include the welfare of fish. Thus, it is important to further explicate the respect for nature based views and help those working in this practice to adjust and translate these (traditional) views to the current practice.

Thirdly, there could be better integration of personal and professional values. When discussing motivations to invest in technological development, stakeholders seemed to be somewhat reluctant to include values other than economic values into their deliberations. Their focus is market driven, so whether there is demand in the market for higher priced products that they can supply. However, it is suggested that from a corporate social responsibility (CSR) standpoint, moral values can also play an important role in a market context. This also includes room for more systematic attention to the welfare of animals, including fish (Janssens \& Kaptein, 2016).

Acknowledgements The study was funded by the Research Council of Norway. We thank the wider research group involved in the current project, Svein Helge Gjøsund, Ulf Erikson, Manu Sistiaga, Hanne Digre, Hans van de Vis and Rolf Erik Olsen, for their feedback and input throughout this study.

Author contributions Both of the authors contributed to the idea and design of the study. Data collection was carried out by DCL. Material preparation and data analysis was performed by both authors. The drafts of the manuscript were written by DCL, with significant contributions and comments from FLBM. Both of the authors have read and approved the final manuscript.

Funding Open access funding provided by SINTEF AS. The Research Council of Norway.

Availability of data and materials Not applicable.

Code availability Not applicable.

\section{Declarations}

Conflict of interest The authors declare that they have no conflict of interest. 
Consent to participate Interviewees gave informed consent to participating in an audio recorded interview.

Consent for publication Interviewees gave informed consent for statements made during the interviews to be published anonymously.

Ethics approval The Norwegian Centre for Research Data (NSD) validated and approved the study before it was carried out and that the data material was handled in accordance with the current General Data Protection Regulation (GDPR).

Open Access This article is licensed under a Creative Commons Attribution 4.0 International License, which permits use, sharing, adaptation, distribution and reproduction in any medium or format, as long as you give appropriate credit to the original author(s) and the source, provide a link to the Creative Commons licence, and indicate if changes were made. The images or other third party material in this article are included in the article's Creative Commons licence, unless indicated otherwise in a credit line to the material. If material is not included in the article's Creative Commons licence and your intended use is not permitted by statutory regulation or exceeds the permitted use, you will need to obtain permission directly from the copyright holder. To view a copy of this licence, visit http://creativecommons.org/licen ses/by/4.0/.

\section{References}

Allen, C. (2013). Fish cognition and consciousness. Journal of Agricultural and Environmental Ethics, 26(1), 25-39.

Arlinghaus, R., Cooke, S. J., Schwab, A., \& Cowx, I. G. (2007). Fish welfare: A challenge to the feelingsbased approach, with implications for recreational fishing. Fish and Fisheries, 8(1), 57-71. https:// doi.org/10.1111/j.1467-2979.2007.00233.x

Ashley, P. J. (2007). Fish welfare: Current issues in aquaculture. Applied Animal Behaviour Science, 104(3), 199-235. https://doi.org/10.1016/j.applanim.2006.09.001

Bovenkerk, B., \& Meijboom, F. (2020). Ethics and the welfare of fish. In T. Kristiansen, A. Fernö, M. Pavlidis, \& H. van de Vis (Eds.), The Welfare of Fish (pp. 19-42). Springer.

Bovenkerk, B., \& Verweij, M. (2016). Between individualistic animal ethics and holistic environmental ethics blurring the boundaries. In B. Bovenkerk \& J. Keulartz (Eds.), Animal ethics in the age of humans. The international library of environmental, agricultural and food ethics (Vol. 23, pp. 369-385). Springer. https://doi.org/10.1007/978-3-319-44206-8_22

Braithwaite, V. A. (2010). Do fish feel pain? Oxford University Press.

Broom, D. M. (2016). Sentience and animal welfare: New thoughts and controversies. Animal Sentience: An Interdisciplinary Journal on Animal Feeling, 1(5), 11.

Browman, H. I., Cooke, S. J., Cowx, I. G., Derbyshire, S. W. G., Kasumyan, A., Key, B., et al. (2019). Welfare of aquatic animals: where things are, where they are going, and what it means for research, aquaculture, recreational angling, and commercial fishing. ICES Journal of Marine Science, 76(1), 82-92.

Chandroo, K. P., Duncan, I. J., \& Moccia, R. D. (2004). Can fish suffer?: Perspectives on sentience, pain, fear and stress. Applied Animal Behaviour Science, 86(3-4), 225-250.

Conte, F. S. (2004). Stress and the welfare of cultured fish. Applied Animal Behaviour Science, 86(3-4), 205-223.

DeGrazia, D. (2008). Moral status as a matter of degree? The Southern Journal of Philosophy, 46(2), $181-198$.

Digre, H., Hansen, U. J., \& Erikson, U. (2010). Effect of trawling with traditional and 'T90'trawl codends on fish size and on different quality parameters of cod Gadus morhua and haddock Melanogrammus aeglefinus. Fisheries Science, 76(4), 549-559.

Digre, H., Rosten, C., Erikson, U., Mathiassen, J. R., \& Aursand, I. G. (2017). The on-board live storage of Atlantic cod (Gadus morhua) and haddock (Melanogrammus aeglefinus) caught by trawl: Fish behaviour, stress and fillet quality. Fisheries Research, 189, 42-54. 
Dutch Council of Animal Affairs. (2018). advisory report: fish welfare. Retrieved Febuary 20, 2018 from https://english.rda.nl/publications/publications/2018/03/07/fish-welfare.

European Commission (EC). (2007). Treaty of Lisbon amending the Treaty on European Union and the Treaty establishing the European Community, signed at Lisbon, 13 December 2007. Retrieved February 26, 2020 from https://eur-lex.europa.eu/legal-content/EN/TXT/?uri=CELEX\%3A12007L\% 2FTXT.

European Union (EU). (2016). Special eurobarometer 442: attitudes of European towards animal welfare. Retrieved February 25, 2020 from https://data.europa.eu/euodp/en/data/dataset/S2096_84_4_442_ ENG.

Francione, G. L., \& Garner, R. (2010). The animal rights debate: Abolition or regulation? Columbia University Press.

Gjøsund, S. H., Hansen, K., Enerhaug, B., Grimaldo, E., \& Sistiaga, M. (2011). Ny skånsom pose for trål og snurrevad (New gentle codend for trawl and seine). SINTEF A22865 (SFH80 A103068).

Goodpaster, K. (2013). On being morally considerable (Ethical theory: An anthology) (2nd ed.). Blackwell Publishers Ltd.

Huntingford, F. A., Adams, C., Braithwaite, V. A., Kadri, S., Pottinger, T. G., Sandøe, P., et al. (2006). Current issues in fish welfare. Journal of Fish Biology, 68(2), 332-372.

Hursthouse, R. (2006). Applying virtue ethics to our treatment of the other animals (The practice of virtue: Classic and contemporary readings in virtue ethics). Hackett Publishing.

Janssens, M. R. E., \& Kaptein, M. (2016). The ethical responsibility of companies towards animals: A study of the expressed commitment of the Fortune Global 200. Journal of Corporate Citizenship, 63, 42-72.

Kaiser, M., \& Huntingford, F. A. (2009). Introduction to papers on fish welfare in commercial fisheries. Journal of Fish Biology, 75(10), 2852-2854.

Kalshoven, K., \& Meijboom, F. L. B. (2013). Sustainability at the crossroads of fish consumption and production ethical dilemmas of fish buyers at retail organizations in the Netherlands. Journal of Agricultural and Environmental Ethics, 26(1), 101-117.

Knutsson, S., \& Munthe, C. (2017). A virtue of precaution regarding the moral status of animals with uncertain sentience. Journal of Agricultural and Environmental Ethics, 30(2), 213-224.

Kupsala, S., Jokinen, P., \& Vinnari, M. (2013). Who cares about farmed fish? Citizen perceptions of the welfare and the mental abilities of fish. Journal of Agricultural and Environmental Ethics, 26(1), 119-135.

Lambooij, E., Digre, H., Reimert, H. G. M., Aursand, I. G., Grimsmo, L., \& Van de Vis, J. W. (2012). Effects of on-board storage and electrical stunning of wild cod (Gadus morhua) and haddock (Melanogrammus aeglefinus) on brain and heart activity. Fisheries Research, 127, 1-8.

Lund, V., Mejdell, C. M., Röcklinsberg, H., Anthony, R., \& Håstein, T. (2007). Expanding the moral circle: farmed fish as objects of moral concern. Diseases of aquatic organisms, 75(2), 109-118.

Lund, T. B., Kondrup, S. V., \& Sandøe, P. (2019). A multidimensional measure of animal ethics orientation-Developed and applied to a representative sample of the Danish public. PLOS ONE, 14(2), e0211656.

Meijboom, F. L. B., \& Bovenkerk, B. (2013). Fish Welfare: Challenge for science and ethics-Why fish makes the difference. Journal of Agricultural and Environmental Ethics, 26(1), 1-6.

Mepham, B. (2000). A framework for the ethical analysis of novel foods: The ethical matrix. Journal of Agricultural and Environmental Ethics, 12(2), 165-176.

Metcalfe, J. D. (2009). Welfare in wild-capture marine fisheries. Journal of Fish Biology, 75(10), $2855-2861$.

Norwegian Council for Animal Ethics. (2014). Etiske vurderinger av fangstmetodene i kommersielt fiske. (Statement: Ethical evaluations of capture methods in commercial fisheries). Retrieved April 30, 2019 from https://www.radetfordyreetikk.no/wp-content/uploads/2014/11/2014-Uttal else-om-etiske-vurderinger-av-fangstmetodene-i-kommersielt-fiske.pdf.

Olsen, S. H., Tobiassen, T., Akse, L., Evensen, T. H., \& Midling, K. Ø. (2013). Capture induced stress and live storage of Atlantic cod (Gadus morhua) caught by trawl: Consequences for the flesh quality. Fisheries Research, 147, 446-453. https://doi.org/10.1016/j.fishres.2013.03.009

Owen, R., Stilgoe, J., Macnaghten, P., Gorman, M., Fisher, E., \& Guston, D. (2013). A framework for responsible innovation. Responsible Innovation: Managing the Responsible Emergence of Science and Innovation in Society, 31, 27-50.

Rose, J. D. (2002). The neurobehavioral nature of fishes and the question of awareness and pain. Reviews in Fisheries Science, 10(1), 1-38. 
Rose, J. D., Arlinghaus, R., Cooke, S. J., Diggles, B. K., Sawynok, W., Stevens, E. D., et al. (2014). Can fish really feel pain? Fish and Fisheries, 15(1), 97-133.

Röcklinsberg, H. (2015). Fish consumption: choices in the intersection of public concern, fish welfare, food security, human health and climate change. Journal of Agricultural and Environmental Ethics, 28(3), 533-551.

Schukken, Y. H., van Trijp, J. C. M., van Alphen, J. J. M., \& Hopster, H. (2019). Staat van het dier: Beschouwingen en opinies over de verschuivende relatie tussen mens en dier in Nederland. Raad voor Dierenaangelegenheden.

Sneddon, L. (2011). Pain perception in fish. Journal of Consciousness Studies, 18(9-10), 209-229.

Stevenson, P., Battaglia, D., Bullon, C., \& Carita, A. (2014). Review of animal welfare legislation in the beef, pork, and poultry industries. FAO Investment Centre. Directions in Investment (FAO) eng no. 10.

Svanes, E., Vold, M., \& Hanssen, O. J. (2011). Environmental assessment of cod (Gadus morhua) from autoline fisheries. The International Journal of Life Cycle Assessment, 16(7), 611-624. https://doi. org/10.1007/s11367-011-0298-2

Taylor, P. W. (1986). Respect for life: A theory of environmental ethics. Princeton University.

Thrane, M., Ziegler, F., \& Sonesson, U. (2009). Eco-labelling of wild-caught seafood products. Journal of Cleaner Production, 17(3), 416-423. https://doi.org/10.1016/j.jclepro.2008.08.007

Turner, D. W., III. (2010). Qualitative interview design: A practical guide for novice investigators. The Qualitative Report, 15(3), 754.

Van der Scheer, L., \& Widdershoven, G. (2004). Integrated empirical ethics: Loss of normativity? Medicine, Health Care and Philosophy, 7(1), 71-79.

Veldhuizen, L. J. L., Berentsen, P. B. M., Bokkers, E. A. M., \& de Boer, I. J. M. (2015). A method to assess social sustainability of capture fisheries: An application to a Norwegian trawler. Environmental Impact Assessment Review, 53, 31-39.

Veldhuizen, L. J. L., Berentsen, P. B. M., De Boer, I. J. M., Van De Vis, J. W., \& Bokkers, E. A. M. (2018). Fish welfare in capture fisheries: A review of injuries and mortality. Fisheries Research, 204, 41-48.

Warren, M. A. (1997). Moral status: Obligations to persons and other living things. Clarendon Press.

Winger, P. D., Eayrs, S., \& Glass, C. W. (2010). Fish behavior near bottom trawls (Behavior of marine fishes: capture processes and conservation challenges). Wiley-Blackwell.

Woodruff, M. L. (2017). Consciousness in teleosts: There is something it feels like to be a fish. Animal Sentience: An Interdisciplinary Journal on Animal Feeling, 2(13), 1-21.

Publisher's Note Springer Nature remains neutral with regard to jurisdictional claims in published maps and institutional affiliations.

\section{Authors and Affiliations}

\section{Danielle Caroline Laursen ${ }^{1}$ (D) $\cdot$ Franck L. B. Meijboom ${ }^{2,3}$ (D)}

1 Department of Seafood Technology, SINTEF Ocean, Postboks 124 Blindern, 0314 Oslo, Norway

2 Department of Population Health Sciences, Sustainable Animal Stewardship, Faculty of Veterinary Medicine, Utrecht University, Postbus 80.166, 3508 TD Utrecht, The Netherlands

3 Faculty of Humanities, Ethics Institute, Utrecht University, Janskerkhof 13, 3512 BL Utrecht, The Netherlands 